\title{
Pinturas faciais dos Boe Bororo: algumas considerações visuais a partir de pesquisa etnográfica, netnográfica e bibliográfica
}

\author{
Facial paintings of the Boe Bororo: some visual \\ considerations from ethnographic, netnographic and \\ bibliographic research
}

\author{
José Francisco Sarmento Nogueira ${ }^{1}$ \\ Neimar Leandro Marido Kiga ${ }^{1}$
}

DOI: http://dx.doi.org/10.20435/tellus.vi43.759

\begin{abstract}
Resumo: Um dos aspectos mais relevantes da riqueza cultural do povo Boe Bororo é a expressão artística, que exibe uma exuberância e sofisticação estética muito própria. Este trabalho iconográfico faz uma delimitação em uma destas expressões, que é a pintura facial. Para isso, este trabalho, de forma introdutória, apresenta a história deste povo e suas divisões parentais, também chamadas de clãs, para que o leitor possa entender a lógica das divisões que esta arte assume em seu contexto cultural. É importante ressaltar que não se trata de uma pesquisa finalizada, pois a grandeza destas pinturas ainda não foram totalmente identificadas. Ela parte de um trabalho Etnográfico, Netnográfico e Bibliográfico, construído por um designer Boe Bororo e por um designer "braedog" (não indígena). Optou-se por utilizar o recurso de ilustração² digital para as representações visuais.
\end{abstract}

Palavras-chave: valorização; povos indígenas; cultura; Boe; grafismo.

Abstract: One of the most relevant aspects of the cultural richness of the Boe Bororo people is the artistic expression, which exhibits an exuberance and aesthetic sophistication of your own. This iconographic work delimits one of these expressions, which is face painting. For this, this work introductively presents the history of these people and their parental divisions, also called clans, so that the reader can understand the logic of the divisions that this art assumes in its cultural context. It is important to note that this is not a completed research, as the greatness of these paintings has not yet been fully identified. It starts from an Ethnographic, Netnographic, and Bibliographic work

${ }^{1}$ Universidade Católica Dom Bosco (UCDB), Campo Grande, Mato Grosso do Sul, Brasil.

${ }^{2}$ As ilustrações foram feitas pelo designer Heitor Oliveira Soares. 
built by a designer Boe Bororo and a "braedog" (non-indigenous) designer. We opted to use the digital illustration resource for visual representations.

Keywords: valorization; indigenous people; culture; Boe; graphics.

\section{BOE BORORO}

O Brasil é um país de grande diversidade étnica, com aproximadamente $254^{3}$ etnias indígenas. Boe é o termo que um determinado grupo étnico se denomina para diferenciar dos demais, inclusive dos não indígenas, podendo ser traduzido para pessoas, gente ou povo. Bororo é um pátio na aldeia, próximo ao Bai managejewu (casa central), pátio das danças, praça onde são realizados vários rituais, como nominação das crianças ou ato de executar alguma representação espiritual e local onde são colocados os restos mortais de algum finado para decomposição durante o funeral. Segundo Scotti e Boffi (2001, p. 11):

A palavra "bororo" significa pátio, praça, aldeia. "Orarimugudoge" é o nome nacional, mas, normalmente, eles se autodenominam BOE (gente). Aceitam o nome Bororo, já consagrado na língua portuguesa e nas demais línguas. Outros nomes utilizados para indicar esse povo, ou grupos pertencentes a ele, são: Coroado, Coxiponês Cabaçal e Bororo da Campanha.

Pelo fato de o Bororo ser uma praça onde acontecem alguns rituais, como de nominação ou danças durante os dolorosos funerais, esse termo era usado com certa frequência entre os Boe, para identificá-los como uma etnia foi colocado esse nome. Esse povo se autodenomina Boe, atualmente preferem ser chamados dessa maneira e estão em processo de mudança do nome.

Os Boe Bororo ${ }^{4}$ têm rituais de grande importância e significado, momentos que são realizados com muito prazer. Para que um boe etore (criança) pertença ao mundo e estar preparado é necessário que passe pelo ritual de nominação. Um povo muito ligado ao mundo espiritual, aroedoge (espíritos) têm o ritual do

3 Disponível em: pib.socioambiental.org/pt/Quadro_Geral_dos_Povos. Acesso em: 16 nov. 2018.

4 Atualmente, os Bororo detêm seis Terras Indígenas demarcadas no Estado de Mato Grosso, num território descontínuo e descaracterizado, que corresponde a uma área 300 vezes menor do que o território tradicional. As TIs Meruri, Perigara, Sangradouro/Volta Grande e Tadarimana estão registradas e homologadas; a TI Jarudori foi reservada aos índios pelos SPI (Serviço de Proteção ao Índio), mas foi sendo continuamente invadida, a ponto de hoje estar totalmente ocupada por uma cidade; já a TI Teresa Cristina está sob júdice, uma vez que sua delimitação foi derrubada por decreto presidencial. 
Pinturas faciais dos Boe Bororo: algumas considerações visuais a partir de pesquisa etnográfica, netnográfica e bibliográfica

funeral onde se conectam entre o mundo físico e espiritual, um dos rituais mais impressionantes da etnia. Para Scotti e Boffi (2001, p. 12):

Em 1902, os Salesianos se dirigiram à localidade "Tachos", onde iniciaram um novo estilo de aproximação dos Bororo, sob a direção do Padre Bálzola. Ele procurou se adaptar ao estilo de vida dos índios, não os obrigando a seguir as regras de vida dos brancos. O sucesso levou os Salesianos a fundarem outras missões: no rio das Garças (1905) e em Sangradouro (1906).

O povo Boe Bororo foi e ainda é uma das etnias mais estudadas no Brasil, por sua grande riqueza cultural e sua vasta diversidade estética. Essa diversidade se aplica aos seus adornos e utensílios, bem como em suas pinturas corporais, com uma grande quantidade de elementos visuais de expressiva organização e harmonia. O pariko (cocar) compõe essa diversidade em cores intensas, outro exemplo é o parikiboto (abanico), um utensílio muito usado por essa etnia.

Para Levi-Strauss (1957, p. 227), “os Bororo são os maiores e os mais belos indígenas do Brasil. Sua cabeça redonda, sua face alongada, com traços regulares e vigorosos, seus ombros de atleta, evocam certos tipos patagões aos quais talvez se liguem, do ponto de vista racial". Atualmente ainda tem um grande porte físico, mas nem tanto como na época que Lévi-Strauss os pesquisou. Com a influência externa sofreram essa mudança biológica ao longo do tempo.

Mesmo com essa influência não perderam seus hábitos, como o da pesca, os Boe são grandes nadadores e pescam muito com o mergulho, trazem a pesca para as mulheres que preparam com grande reciprocidade. Em sua subsistência, como dito anteriormente, são grandes pescadores e também praticam a caça para se alimentar.

As mulheres vivem por meio do artesanato com suas grandes habilidades. Entre os modos de sustento, trazem também a coleta de frutas silvestres, trabaIham com roça de toco, plantam mandioca, milho, feijão, banana, mamão etc. Criação de gado e animais domésticos, muitas trabalham como funcionárias das áreas de Educação e Saúde, e na Funai e na Missão Salesiana.

A população do povo Boe Bororo em séculos passados era estimada em 10 mil pessoas. Ao longo dos anos, esse número reduziu drasticamente, mas esse povo conseguiu resistir e recentemente sua população voltou a crescer. Houve também uma grande mudança em seu espaço territorial, ocupando uma pequena parcela do seu território anterior. Para Aguilera Urquiza (2012, p. 273): 
O povo Bororo, que se autodenomina Boe, que ocupava até fins do século XVIII grande parte do centro sul do atual estado de Mato Grosso, após mais de um século de contato intermitente com o entorno regional e com a atuação de missionários salesianos e de órgãos do Estado, na atualidade estão reduzidos a um pouco mais de mil pessoas vivendo em 6 terras indígenas.

A terra é fundamental para os povos indígenas, dela extraem vários recursos para sua subsistência. As terras indígenas são usadas de diversas formas, é de onde tiram o alimento, como a caça, pesca e coleta de frutas. Vários de seus rituais dependem da natureza, pela extração de algum vegetal. Este mesmo o espaço serve para seus rituais. Ao mesmo tempo em que usam o território para diversos fins, estão em constante preocupação para que as próximas gerações usem a terra com a mesma finalidade.

Na complexa organização social dos Bororo a classificação dos indivíduos é feita a partir de seu clã, da linhagem e do grupo residencial. A regra de descendência é matrilinear, de modo que, ao nascer, a criança receberá um nome que a identificará ao clã de sua mãe. Embora exista essa norma ideal de conduta, na prática ela pode ser manipulada para atender outros interesses (NOVAES, 1986).

Após esta brevíssima apresentação do povo Boe, partimos para as questões iconográficas, que são os objetivos deste trabalho. Para o início do trabalho iconográfico, começamos por escolher as pinturas.

\section{ESCOLHA DAS PINTURAS}

O uso das mídias digitais sociais, foram fundamentais para as definições das pinturas que iriamos apresentar neste trabalho. O recurso Netnográfico nos possibilitou uma pesquisa-ação junto a este povo, pois foram as suas participações e suas escolhas que definiram os desenhos que iriamos ilustrar. Para escolha das pinturas, fizemos um formulário com três pinturas de cada clã e o enviamos pelo Facebook ${ }^{5}$ e WhatsApp ${ }^{6}$ para as pessoas de determinados clãs. A partir de

5 É uma das mídias sociais mais utilizadas em todo o mundo como espaço de partilha, de interação e de discussão de ideias. Disponível em: http://books.scielo.org/id/c3h5q/pdf/porto-9788578792831-05.pdf. Acesso em: 16 nov. 2018.

6 Uma das mídias sociais mais conhecidas e utilizadas de comunicação instantânea no mundo, chegando a superar a marca de 1,2 bilhão de usuários, 2 bilhões de fotos compartilhadas, 250 milhões de vídeos, mais de um bilhão de grupos; considerando que o Brasil é o país que mais tem 
Pinturas faciais dos Boe Bororo: algumas considerações visuais a partir de pesquisa etnográfica, netnográfica e bibliográfica

suas escolhas, continuamos o trabalho. O objetivo foi fazer com que as próprias pessoas de cada clã escolhessem as pinturas que mais os representavam, para que nós pudéssemos nos sentir mais confortáveis com a escolha e o resultado do trabalho. Para tanto, criamos um formulário para os participantes.

Badojeba - no primeiro momento, pensamos em trazer para o material os grafismos que eram mais relacionados à natureza, que tivessem um traço representando alguma ave ou animal. A relações com esses elementos eram mais fáceis de reproduzir, pela presença mais frequente em nosso cotidiano, e até mesmo em materiais gráficos que serviriam como referência para realização do trabalho. A partir dessa mudança, evoluímos de forma bem justa, tanto para nós quanto para nosso público, que são os Boe Bororo.

O subclã dos Badojeba é um dos populosos entre os Boe Bororo, principalmente na aldeia Meruri. Essa quantidade de pessoas ajudou bastante para realização desta pesquisa. Uma grande quantidade de pessoas desse subclã mora na aldeia Meruri ${ }^{7}$, origem de um dos autores deste trabalho, que conhece todas as pessoas e sabe à qual clã pertencem, mantendo contato com a maioria pelas redes sociais, como o Facebook, e com alguns, pelo WhatsApp. No momento em que decidimos realizar a pesquisa, não pensamos como seria a devolutiva, algumas pessoas ignoraram o questionário, mas a maioria se interessou e respondeu, contribuindo significativamente para realização deste trabalho.

grupos, surgem então cada vez mais possibilidades e novos contextos de aprendizagem que rompem os muros da escola. Disponível em: https://site.ucdb.br//public/md-dissertacoes/1022568-willian-veron.pdf. Acesso em: 16 nov. 2018.

7 https://terrasindigenas.org.br/pt-br/terras-indigenas/3767 
Figura 1 - Formulário do clã dos Badojeba

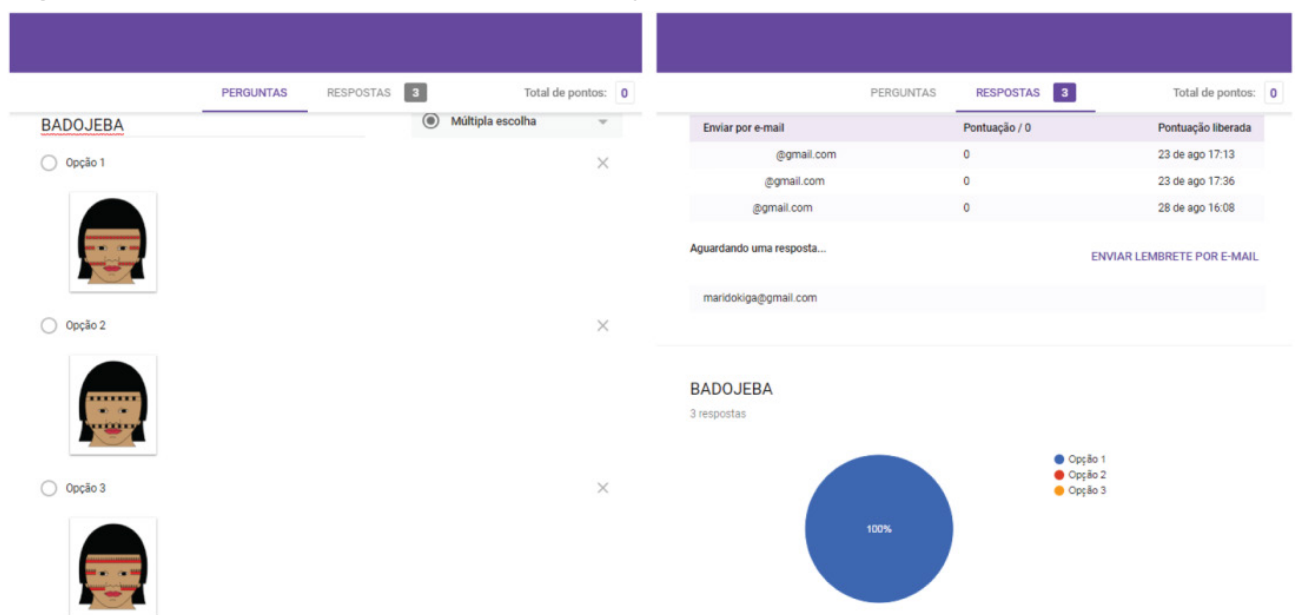

Fonte: Os autores (2018).

Bakoro Ečerae - esse clã é um dos que a população é menor entre os Boe Bororo, então a quantidade de respostas foi menor ao anterior. Vale lembrar que os grafismos podem ser usados pelo clã da mãe e do pai, então nesse subclã foi necessário enviar aos filhos dos homens Bakoro Ečerae para completar a pesquisa. Eles trouxeram na escolha, um grafismo pouco usado pela falta de pessoas, mas, um dos mais bonitos e todos escolheram o mesmo.

Figura 2 - Formulário do clã dos Bakoro Ečerae

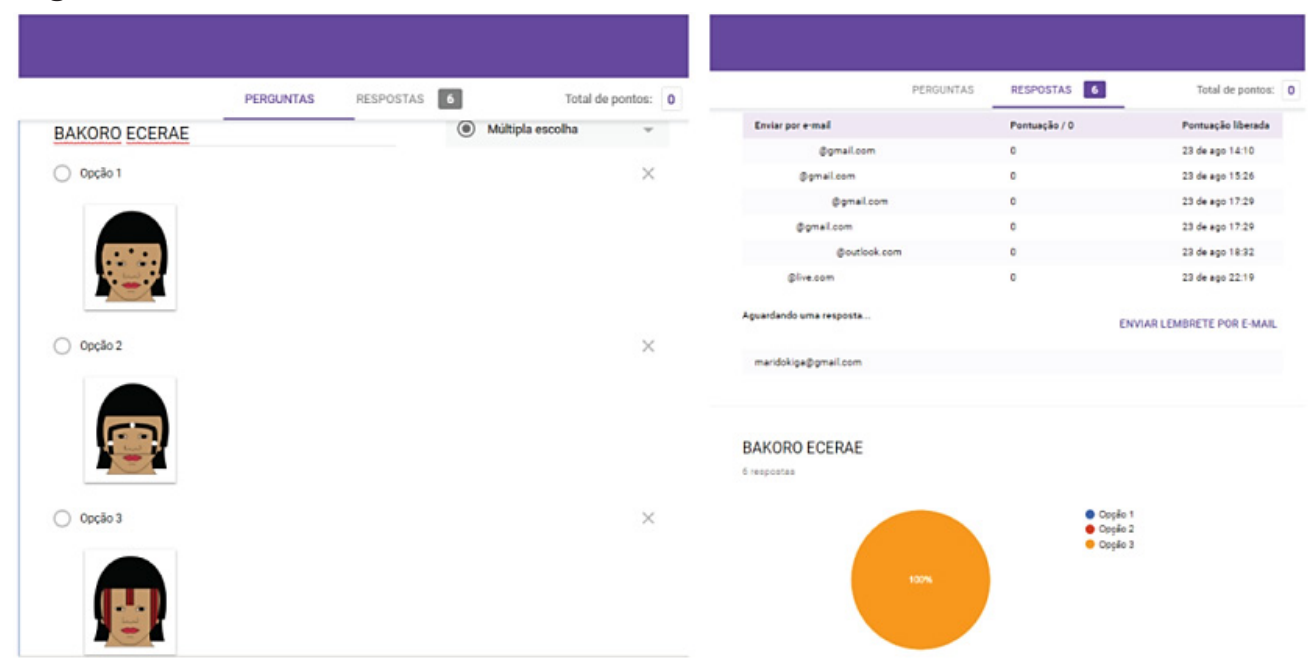

Fonte: Os autores (2018). 
Pinturas faciais dos Boe Bororo: algumas considerações visuais a partir de pesquisa etnográfica, netnográfica e bibliográfica

Bokodori Ečerae - este subclã tem uma grande quantidade de pessoas, semelhante aos Badojeba. O que mais facilitou a pesquisa foi a inserção dessas pessoas nas tecnologias digitais, muitas pessoas desse subclã estão conectadas no Facebook e WhatsApp, no qual enviamos os formulários, facilitando o resultado. E pela pesquisa dar voz ao que eles queriam e se sentiam representados.

Figura 3 - Formulário do clã dos Bokodori Ečerae

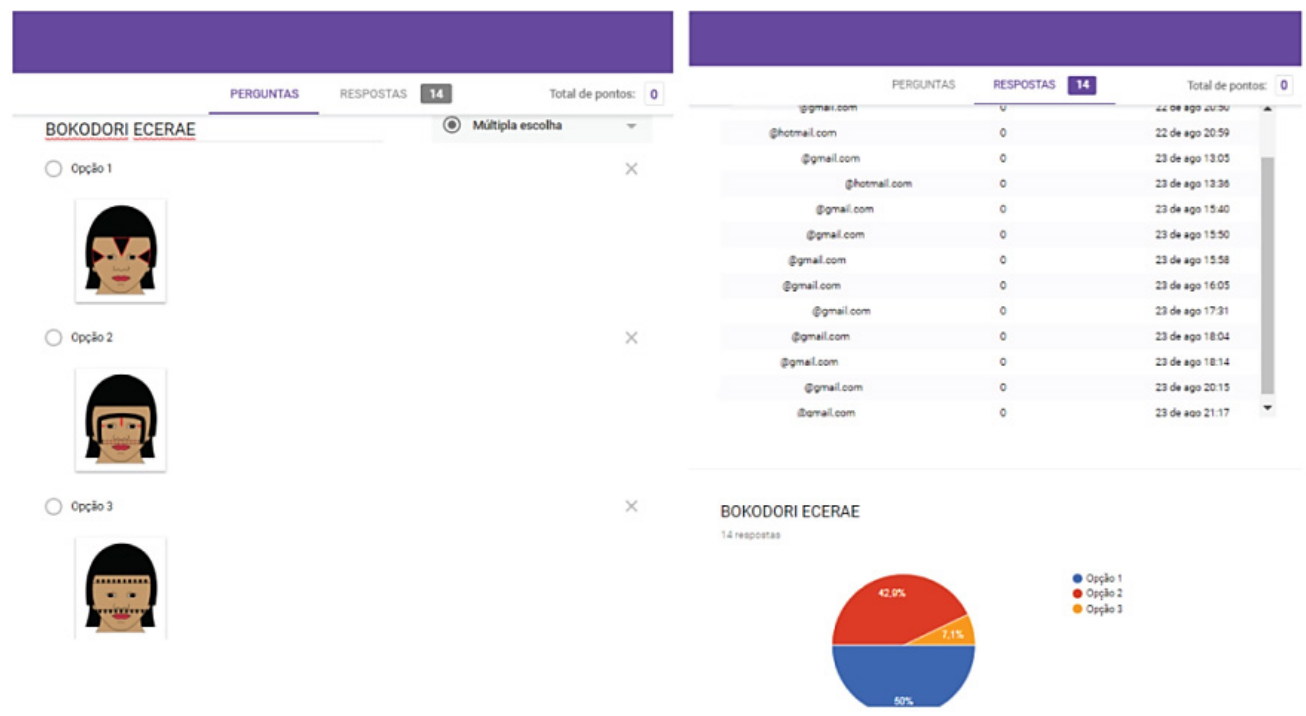

Fonte: Os autores (2018).

Kie - os componentes desse subclã não têm uma quantidade muito grande de pessoas. Como no caso dos Bakoro Ečerae buscou-se os filhos dos homens desse subclã para que a pesquisa fosse realizada, mesmo com poucas respostas foi suficiente e de grande importância. 
Figura 4 - Formulário do clã dos Kie

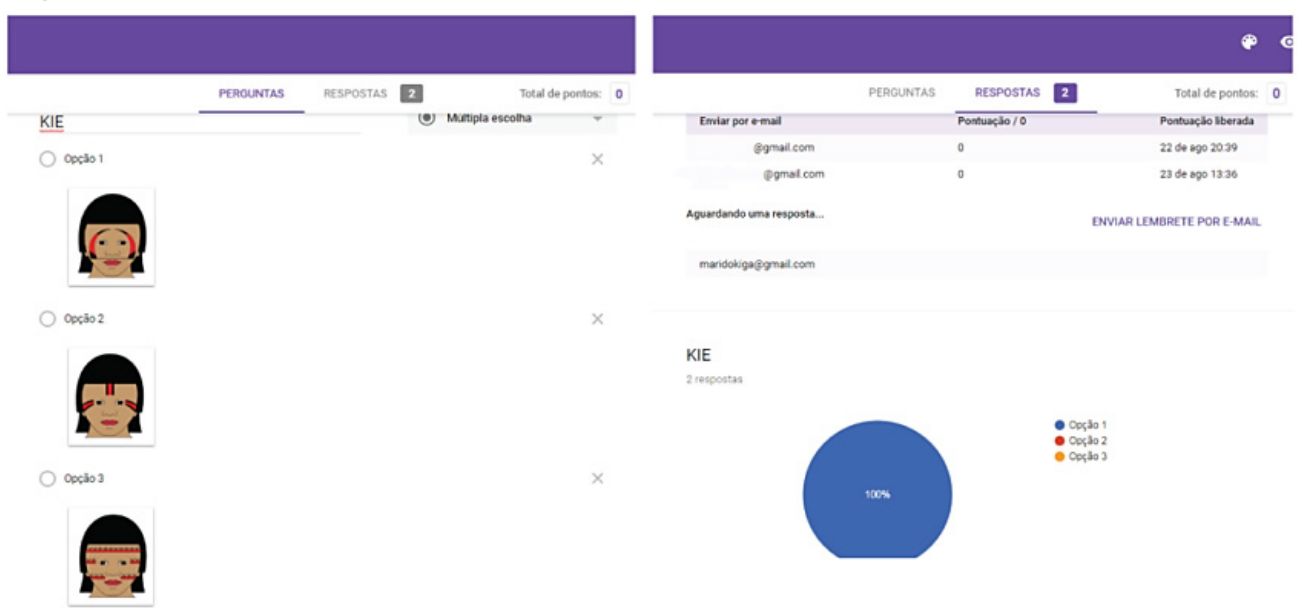

Fonte: Os autores (2018).

Apiborege - é um dos subclãs de maior população entre os Tugarege. Por esse motivo, tivemos uma devolutiva bem expressiva do formulário. Essa quantidade de pessoas nos fez pensar em trazer para o material os grafismos que eram mais usados por esse subclã no início da escolha.

Figura 5 - Formulário do clã dos Apiborege

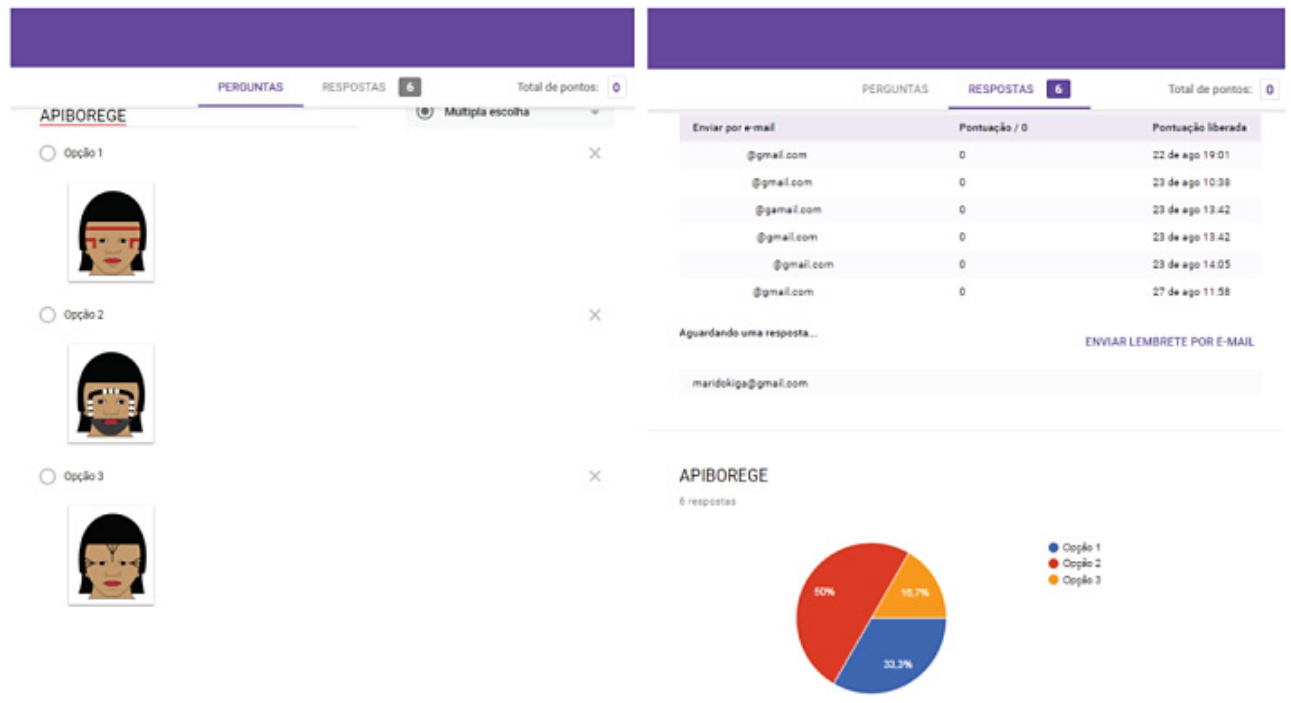

Fonte: Os autores (2018). 
Pinturas faciais dos Boe Bororo: algumas considerações visuais a partir de pesquisa etnográfica, netnográfica e bibliográfica

Aroroe - foi o único subclã que conseguimos obter apenas uma resposta. A quantidade de pessoas desse subclã na aldeia Meruri é bem pequena, local onde a maioria das pessoas pesquisadas moram.

Figura 6 - Formulário do clã dos Aroroe

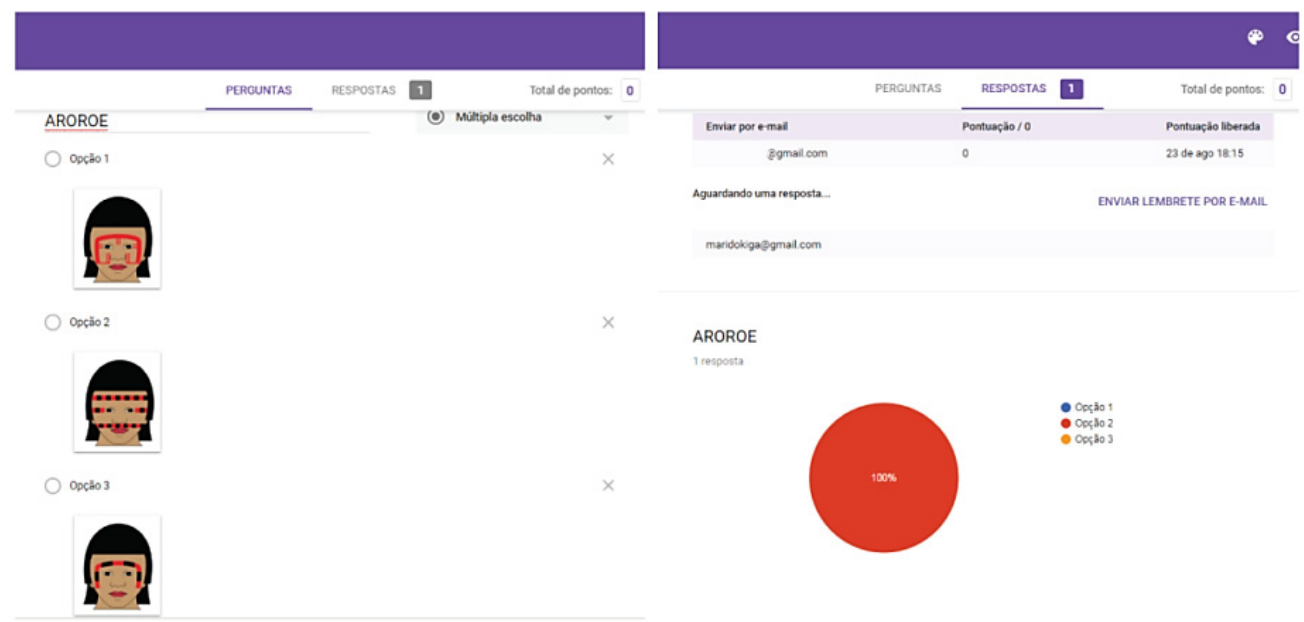

Fonte: Os autores (2018).

Iwagudu - a escolha do grafismo deste subclã não foi feita pelo formulário. Pelo fato de um integrante do trabalho pertencer a esse clã e ter contato maior com as pessoas, que não são muitas, resolvemos enviar pelo WhatsApp as fotos dos grafismos e eles nos respondiam mostrando qual mais gostaram. O integrante do trabalho pertencente a esse clã comenta que o grafismo mais agradável para ele era um que não foi escolhido, mas o que prevaleceu foi a escolha da maioria. Paiwoe - para a escolha dos grafismos inicialmente pensamos em colocar as que tinham relações com os espíritos, pelos Boe Bororo terem uma relação com o mundo espiritual e para que não perdessem essa tradição e ainda pela facilidade em sua reprodução.

Tivemos contato com poucas pessoas do subclã dos Paiwoe, mas conseguimos o resultado que desejávamos desde o início da pesquisa. No momento da escolha dos grafismos no link do formulário, por algum motivo não conseguiram responder, mas conseguimos o resultado por meio do Facebook, pela numeração dos grafismos no link nos responderam. 
Percebemos, por meio das respostas na pesquisa, o interesse das pessoas no assunto abordado, elas trouxeram resultados positivos para a pesquisa. Não somente na pesquisa, mas ajudaram também na construção do material, na caracterização do povo Boe Bororo. Sempre que possível, enviamos as ilustrações e os ícones das matérias-primas para uma resposta que poderia contribuir no trabalho.

Figura 7 - Formulário do clã dos Paiwoe

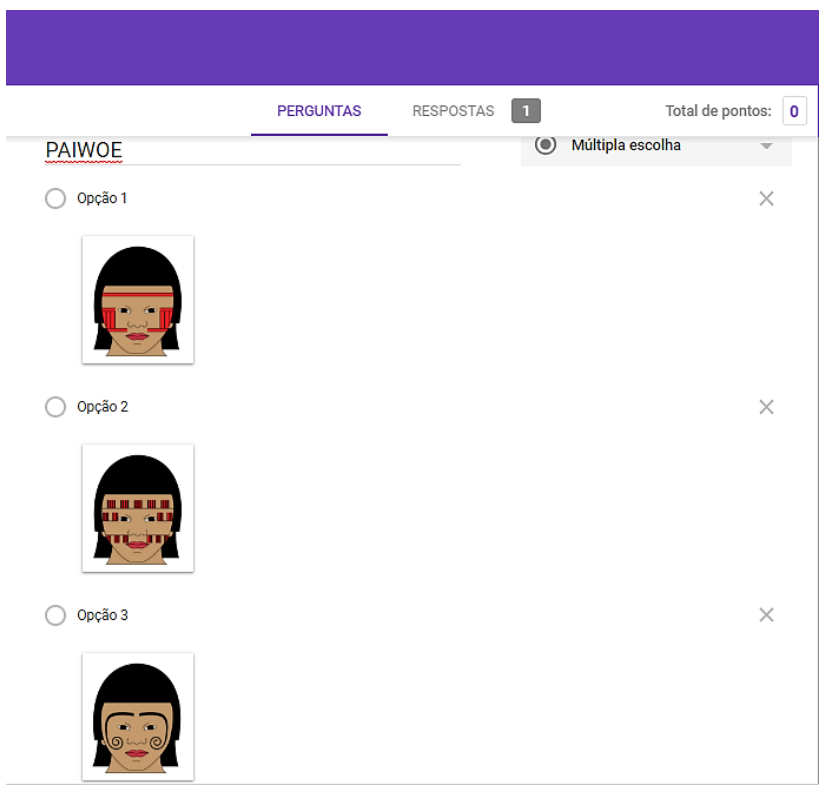

Fonte: Os autores (2018).

\section{MATÉRIAS-PRIMAS USADAS NAS PINTURAS FACIAIS}

Para que os grafismos estejam nos corpos dos Boe durante seus diversos rituais, eles precisam ser extraídos da natureza e produzidos para a pintura. Faremos uma pequena introdução a esses materiais.

Akiri é uma penugem branca de aves, geralmente pato e mutum, que é colada com kido guru na margem de certos riscos, ou reveste determinadas regiões do rosto.

Ičira é um palito usado nas pinturas faciais como pincel, é tirado da palha de buriti; como é resistente, ele facilita na hora da pintura. 
Pinturas faciais dos Boe Bororo: algumas considerações visuais a partir de pesquisa etnográfica, netnográfica e bibliográfica

Irogodu é um pó de carvão temperado com água e às vezes com kido guru, frequentemente é obtido de determinado - jorubo, vegetal mágico.

Kido guru é a resina de uma Burseraceae que dá um verniz quando misturada com pó de carvão.

Noa é uma argila branca que umedecida com água é diretamente aplicada sobre a pele, também pode ser usada a cinza de caramujo para obter a cor branca.

Nonogo é uma pasta vermelha à base de urucum, para seu preparo.

\section{GRAFISMOS FACIAIS, A PARTIR DA ESCOLHA DOS MEMBROS QUE CONTRIBUÍRAM COM A PESQUISA}

Figura 8 - Ilustração do clã dos Badojeba

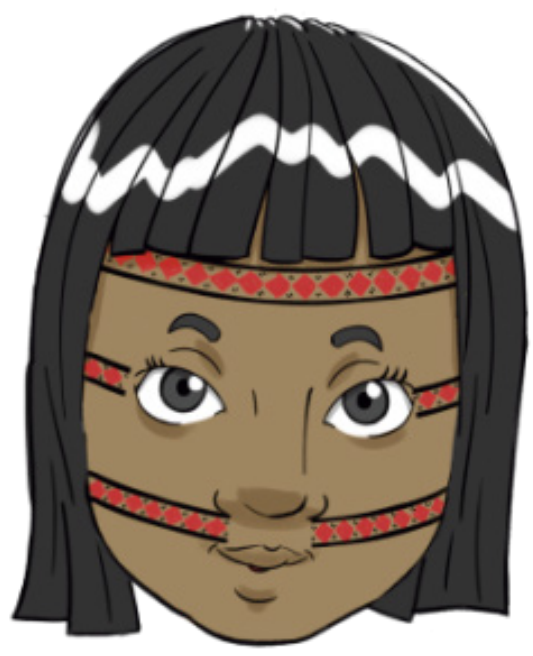

Fonte: Ilustração do designer Heitor Oliveira Soares.

Badojeba, Buregodureuge edugo - representação do espírito Buregodureuge. 
Figura 9 - Ilustração do clã dos Bakoro Ečerae

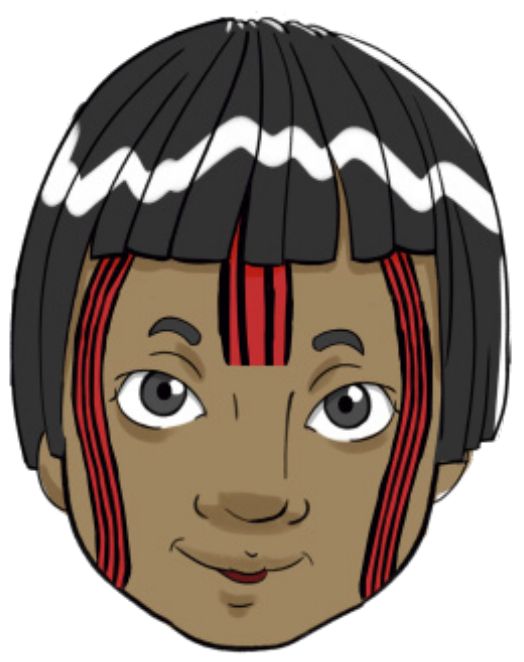

Fonte: Ilustração do designer Heitor Oliveira Soares.

Bakoro Ečerae, Enogujeba edugo - representação do espírito Enogujeba. Esses espíritos antigamente viviam com os Boe, eles sempre avisavam o que estava por vir ao seu povo, para que pudessem sair de determinado local e ir em busca de um lugar melhor, tornando-os, assim, nômades.

Figura 10 - Ilustração do clã dos Bokodori Ečerae

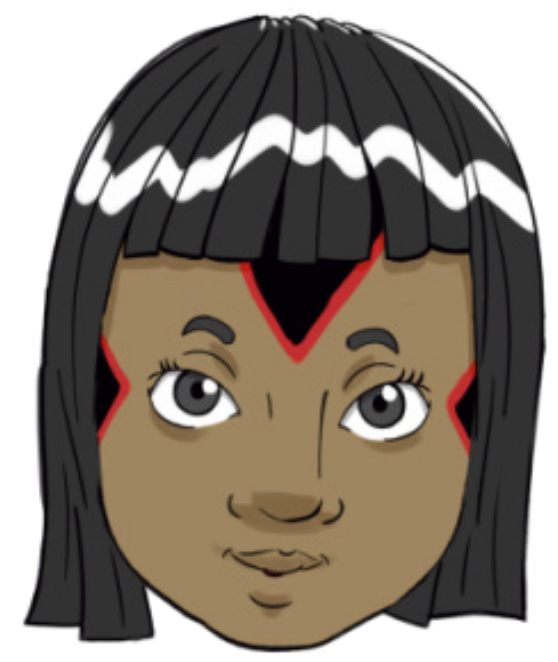

Fonte: Ilustração do designer Heitor Oliveira Soares. 
Pinturas faciais dos Boe Bororo: algumas considerações visuais a partir de pesquisa etnográfica, netnográfica e bibliográfica

Bokodori Ečerae, Koge bure - Koge: peixe dourado, bure: pé ou cauda (cauda do peixe dourado). Todos os clãs têm seus determinados animais, aves e espíritos; a partir deles, fazem suas pinturas para que, ao realizarem algum ritual ou ao se ornamentarem, os representem. Essa pintura se parece muito com uma pintura do clã dos Iwagudu, mas o seu formato é um pouco maior.

Figura 11 - Ilustração do clã dos Kie

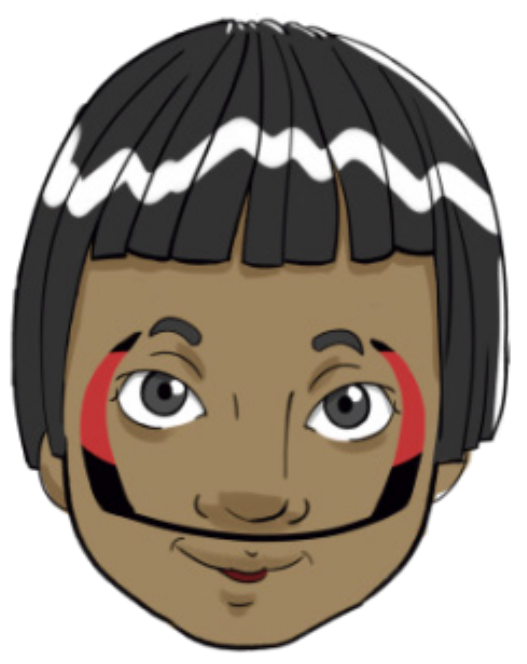

Fonte: Ilustração do designer Heitor Oliveira Soares.

Kie, Apodo oto - apodo: tucano, oto: bico (bico de tucano). É a parte superior do bico do tucano, um risco preto de verniz de carvão atravessa horizontalmente toda a face logo abaixo do nariz, de cada uma de suas extremidades nascem para cima dois traços pretos que se vão unir o meio da testa. O espaço entre os dois traços é pintado com faixa vermelha de urucum que faz parecer como dois bicos de tucano. Serve de adorno. 
Figura 12 - Ilustração do clã dos Apiborege

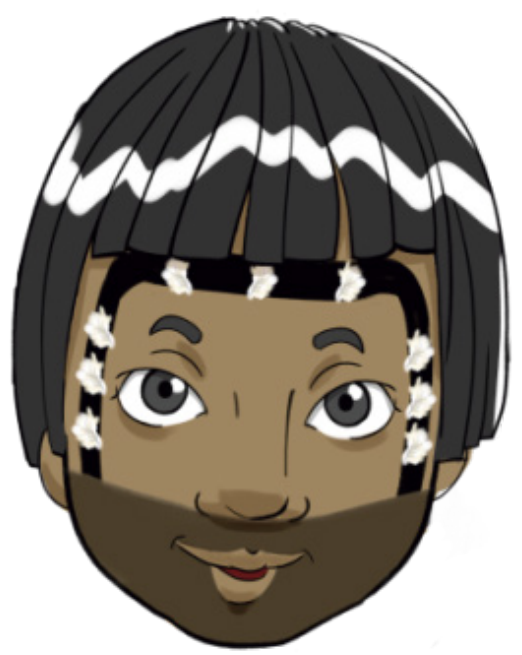

Fonte: Ilustração do designer Heitor Oliveira Soares.

Apiborege, Kuruguga oiaga atugo - pintura da cauda do gavião Caracará. Usam a beleza dessa ave para se pintarem, visto que a ave pertence ao clã. Nesse grafismo, tentam imitar essa ave e fazem isso por meio de suas cores, usam o preto e branco, não se encontra o urucum no grafismo pelo fato da ave não ter a cor vermelha em suas penas. E, como podemos observar, a ave tem as penas pretas na parte de cima da cabeça e abaixo do pescoço, e o grafismo tem essas características em sua representação, assemelhando-se ainda mais com o gavião Caracará. 
Pinturas faciais dos Boe Bororo: algumas considerações visuais a partir de pesquisa etnográfica, netnográfica e bibliográfica

Figura 13 - Ilustração do clã dos Aroroe

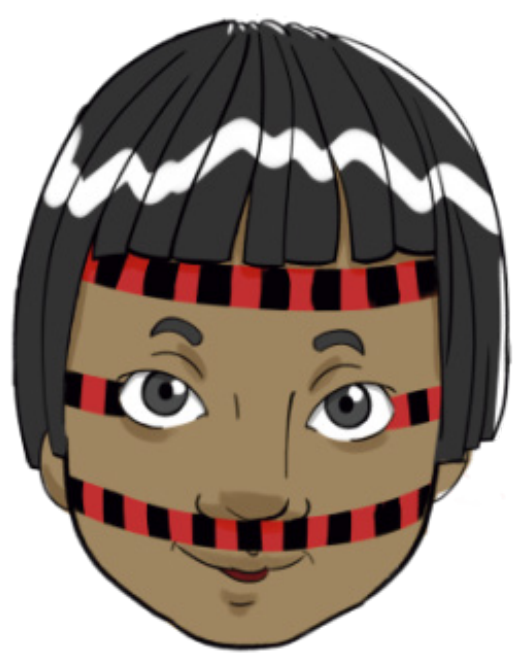

Fonte: Ilustração do designer Heitor Oliveira Soares.

Aroroe, Aroro atugo - listra de determinada lagarta. A lagarta é a representação do clã dos Aroroe; nessa pintura, suas características tentam imitar esse inseto. Essas listras também são colocadas no pariko dos Boe, na parte onde fica a cabeça. É uma lagarta que pode chegar a 15 centímetros de comprimento, sua cor é preta, com listras verde-claras, e as patas e a cabeça laranja. 
Figura 14 - Ilustração do clã dos Iwagudu

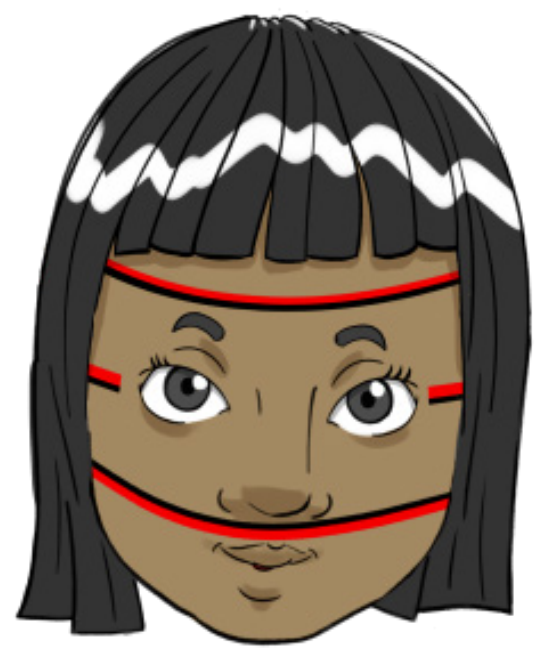

Fonte: Ilustração do designer Heitor Oliveira Soares.

Iwagudu, Jakomea atugo - representação do espírito Jakomea. Esse espírito pertence ao clã dos Iwagudu; muito tempo atrás, causou uma grande inundação no planeta, quando foi flechado por um menino que estava bravo com alguns homens da aldeia. Um espírito das águas, é muito colorido, traz suas cores na pintura.

Figura 15 - Ilustração do clã dos Paiwoe

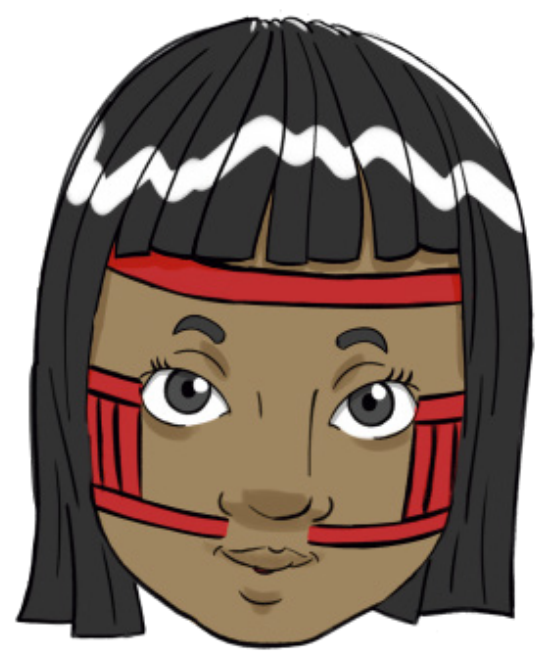

Fonte: Ilustração do designer Heitor Oliveira Soares. 
Pinturas faciais dos Boe Bororo: algumas considerações visuais a partir de pesquisa etnográfica, netnográfica e bibliográfica

Paiwoe, Itobaga atugo - designação do espírito Itobaga. Alguns Boe não gostavam dos espíritos e, por esse motivo, eles deixaram de viver no mundo em que nós estamos, mas sempre estão dispostos a ajudar os que confiam e acreditam neles. Essa pintura pode ser colocada no verso da pele seca de alguma onça.

\section{CONCLUSÕES PRELIMINARES}

O grafismo é uma estrutura gráfica muito importante e fundamental de qualquer etnia indígena. Ele faz parte das representações de sua cosmovisão, de sua relação com a natureza e o sagrado. Felizmente, a grande maioria dos povos indígenas preserva e dá continuidade a essa prática. Atualmente, pode-se atribuir também ao grafismo uma marca de resistência, de luta e trajetória. Estes elementos sempre estiveram presentes entre os povos, como meio de comunicação, desde as pinturas rupestres; como forma de ornamentação, em utensílios domésticos; e com suas diversas funções em pinturas faciais e corporais.

O conhecimento desses elementos gráficos ainda é pequeno por parte da cultura ocidental, que os vê apenas como um adorno exótico. Trabalhos que mostram seus significados, sua complexidade e entendimento ajudam a mudar este olhar. É de grande satisfação colaborar com a preservação, valorização e visibilidade de uma cultura tão rica como a cultura do povo Boe, apresentando uma pequena parcela do conhecimento tradicional da etnia e sua expressão artística. É um incentivo à própria cultura, visto que, com o processo de colonização, ao longo do tempo, o povo Boe foi fortemente obrigado a não realizar suas práticas culturais, mas resistiu até os dias atuais e resistirá ainda por muito tempo.

\section{REFERÊNCIAS}

NOVAES, Sylvia Caiuby. Mulheres, homens e heróis: dinâmica e permanência através do cotidiano da vida Bororo. São Paulo: FFLCH/USP, 1986. 244 p. (Antropologia, v. 8). [Apresentado originalmente como Dissertação de Mestrado. USP, 1979].

LEVI-STRAUSS, Claude. Tristes Trópicos. São Paulo: ANHEMBI, 1957.

SCOTTI, Osvaldo; BOFFI; Giulio. A Epopéia Bororo. Campo Grande, MS: UCDB, 2001.

AGUILERA URQUIZA, Antonio Hilario. Civilizar o índio: a dupla face da catequese positivista 
na prática dos missionários entre o povo Bororo no Mato Grosso. In: MARIN, Jérri Roberto (Org.). Religiões e identidades. Dourados: Ed. UFGD, 2012. p. 259-78.

\section{Sobre os autores:}

José Francisco Sarmento Nogueira: Doutor em Educação pela Universidade Católica Dom Bosco (UCDB). Mestre e graduado em Design pela Pontifícia Universidade Católica do Rio de Janeiro (PUC-Rio). Professor na graduação e professor colaborador do programa de Pós-Graduação Stricto Sensu: Mestrado e Doutorado em Psicologia e pesquisador do Núcleo de Estudos e Pesquisas das Populações Indígenas (NEPPI) na UCDB. Tem investigado sobre as tecnologias digitais (TICS) em comunidades tradicionais, assim como o grafismo e a cultura material de comunidades autóctones. E-mail: josefsarmento@gmail.com, Orcid: https://orcid.org/0000-0001-5956-5602

Neimar Leandro Marido Kiga: Mestrando em Antropologia pela Universidade Federal de Mato Grosso do Sul (UFMS). Graduado em Design pela Universidade Católica Dom Bosco (UCDB). Pertence ao povo Boe. E-mail: maridokiga@gmail.com, Orcid: https://orcid.org/0000-0003-2112-0733

Recebido em: 3 de julho de 2020.

Aprovado para publicação: 3 de novembro de 2020. 